\title{
Sedentary behaviors and psychological outcomes among older adults: a systematic review
}

\author{
André Ramalho ${ }^{1 *}$, João Petrica1 ${ }^{\text {António Rosado }}{ }^{2}$
}

REVIEW ARTICLE

\begin{abstract}
This systematic review aimed to synthesize the scientific evidence about the relationship between sedentary behaviours and various psychological outcomes in older adults. The study searches were conducted in the following databases: PubMed, PsycINFO, ISI Web of Knowledge and ScienceDirect. We selected 15 observational quantitative studies according to specific eligibility criteria. The data extraction was performed independently by different authors, including the evaluation of the risk of bias of the studies and the classification of the force of evidence. The results showed a tendency of showing no associations between the sedentary behaviours, the well-being and quality of life of the elderly. Concerning life satisfaction and perceived stress, it seems that active sedentary activities have positive effects on these indicators. Evidence has also suggested that some sedentary behaviours may help maintain some cognitive functions in the elderly population, namely in different types of memory. In other studies, it has been demonstrated a tendency that too much time in passive sedentary activities has been associated with depressive symptomatology. However, this review suggested that the evidence is not yet consistent in the relationship between the sedentary behaviours of the elderly and the indicators analysed, and more research is needed.

Keywords: sitting time, psychosocial resources, aging.
\end{abstract}

\section{INTRODUCTION}

Epidemiological research on sedentary behaviours has shown that the consequences for health are independent of those attributed to lack of physical activity (Owen et al., 2011).

In order to obtain a better conceptual understanding, it is important to highlight the differences between the following concepts: sedentary behaviours and physical inactivity. The term physical inactivity is used to describe individuals who do not meet the recommended levels of moderate to vigorous intensity physical activity (Sedentary Behaviour Research Network, 2012). On the other hand, the sedentary behaviours are the wakeful activities characterized by an energy expenditure of less than 1,5 MET (metabolic equivalents) when in the seated or reclined position (Sedentary Behaviour Research Network, 2012). In this way, the sedentary behaviours are the high volumes of time that adults spend seated in the remaining "no exercise", waking hours (Owen, Bauman, \&
Brown, 2009). In this way, an individual can be sufficiently active according to the recommendations of physical activity practice and yet have an extended time of sitting time (Owen et al., 2011). Through the objective measurement (accelerometers), it was concluded that most people's day is dedicated to low intensity physical activity and $55 \%$ of the day in use in sedentary behaviours (Matthews et al., 2008). In this way, understanding why people are physically inactive contributes to evidence-based planning of public health interventions (Bauman et al., 2012). In this sense, sedentary behaviours in the aging population have been associated with premature death, and there is data showing that the reduction of the total time spent in sedentary behaviours may be as important as increased participation in physical activity in reducing health risks (Katzmarzyk, Church, Craig, \& Bouchard, 2009). Effectively, Stamatakis, Davis, Stathi, and Hamer (2012), concluded that sedentary behaviours are associated with

\footnotetext{
Manuscript received at July 20 ${ }^{\text {th }} 2017$; Accepted at September $20^{\text {th }} 2017$

${ }^{1}$ Sport, Health E Exercise Research Unit, SHERU, Instituto Politécnico de Castelo Branco, Castelo Branco, Portugal

${ }^{2}$ Faculty of Human Kinetics - University of Lisbon, Lisbon, Portugal

* Corresponding author: Av. Pedro Álvares Cabral 12, 6000-084 Castelo Branco E-mail: andre.ramalho@ipcb.pt
} 
cardiometabolic risk factors. In fact, the elderly are too long exposed to sedentary behaviour as Harvey, Chastin, and Skelton (2015) reported. The results indicated that the elderly are sedentary on average 9.4 hours per day (Harvey et al., 2015).

The potential consequences of sedentary behaviour in mental health is not well known and more research is needed (Faulkner \& Biddle, 2013). Previous systematic reviews have aimed to analyse the evidence of the association between sedentary behaviours and multiple health indicators in the elderly population (Rezende, Rey-López, Matuso, \& Luiz, 2014) and to understand the determinants of the sedentary behaviour of the elderly (Chastin et al., 2015). However, the previous reviews did not have as main objective to analyse in detail the evidence of the associations between sedentary behaviours and several psychological factors in the elderly population. In addition, other reviews verified the associations between sedentary behaviour and mental health indicators in adolescents (Hoare, Milton, Foster, \& Allender, 2016) and anxiety symptoms in the adult population (Teychenne, Costigan, \& Parker, 2015). Thus, it seems useful to obtain knowledge about the relationships between the sedentary behaviours of the elderly and several psychological indicators, in order to identify which indicators have a greater or lesser value of association with these behaviours. Thus, this systematic review of literature aimed to synthesize the scientific evidence about the relationship between diverse sedentary behaviours and various psychological outcomes in older adults.

\section{METHOD}

The guidelines were followed from the original checklist of the PRISMA - Preferred Reporting Items for Systematic Reviews and Meta-Analyses (Moher, Liberati, Tetzlaff, \& Altman, 2009).

\section{Literature research}

The studies were conducted from September $1^{\text {st }}$ to November $30^{\text {th }}$ of 2016 in four electronic databases (PubMed, PsycINFO, ISI Web of Knowledge and ScienceDirect). We used keywords associated with three areas: 1) sedentary behaviour or related terms; 2) types of sedentary behaviour; 3) possible psychological indicators related to sedentary behaviour. The keywords were always associated with the following words: "elderly" OR "aging" OR "gerontology". In addition to the searches in the electronic databases, reference lists of studies found were analysed in order to identify new studies that could fit the intended.

\section{Eligibility criteria and selection of studies}

Regarding the selection criteria of the studies, the following were considered: 1) empirical studies that investigated sedentary behaviours of the elderly and several psychological indicators (studies published in congress proceedings, theses, book chapters and unpublished manuscripts were not considered) through observational (cross-sectional and longitudinal) quantitative studies and experimental studies (randomized controlled trials and quasiexperimental trials); 2) studies that investigated associations between sedentary behaviours and several variables (e.g., physiological variables) but which included psychological indicators; 3) studies whose average age of the participants was equal to or greater than 65 years old and that the minimum age of the subjects was from 60 years old; 4) studies published in English-language and peer-reviewed journals; 5) studies published from January 2000 to November 2016; 6) studies that presented instruments of measurement on the total time of sedentary behaviours or the time spent in specific sedentary behaviours; 7) studies whose instruments of psychological assessment presented adequate evidence of psychometric validation. We excluded studies that investigated sedentary behaviours in the elderly with specific pathologies.

The studies were imported into the software EndNote (ThompsonReuters, San Francisco, CA, EUA) and the duplicate articles were removed using the "duplicate" function. The selection process of the studies was performed in the following phases: in the initial phase, two independent reviewers based on the titles performed the research of the potentially relevant studies. In case of doubt about the inclusion of 
the studies, these were selected for the next evaluation phase. In the second phase, the abstracts of the studies selected in the initial phase were analysed by two reviewers. In the event of disagreement over the inclusion of studies in the next phase, these were resolved through mediation by a third reviewer. In the third and final phase, the studies selected in the previous phases were reviewed in their entirety by three independent reviewers, taking into account the specific eligibility criteria. At this stage, disagreements among reviewers on the inclusion of studies were resolved by consensus.

\section{Extraction of data and risk of bias in individual studies}

The three reviewers involved in the selection of the studies participated independently in extracting the data from the selected studies. The characteristics of the studies that included their authors, the country where the study was carried out, the methodological design, the characteristics of the participants, the instrument for assessing the sedentary behaviours, the instruments for evaluating the psychological indicators, the results and the conclusions of the studies were registered. At this stage the divergences about the extracted data were overcome by consensus among the reviewers.

Careful assessment of risk of bias is required in each observational study that explains its unique context in order to assess the validity of the estimates of studies (Vandenbroucke, 2011). The risk of bias of the studies was estimated using the RTI item bank (Viswanathan, Berkman, Dryden, \& Hartling, 2013). However, the RTI item bank was adapted to meet the characteristics of the studies included in the review. In this way, the following items of bias analysis were considered: selection bias, selection bias confounding, detection bias confounding, attrition bias, selective outcome reporting, confounding and overall assessment. The evaluation of the items was based on the following responses: "yes"; "no"; "partial"; "impossible to determine"; "not applicable". The text box included in each item was used to document the explanations about the evaluations for further review (Viswanathan et al., 2013). In this way, according to all the answers of the items and their explanations, the studies were classified (good; fair; poor) by an adaptation of the criteria suggested by Balk et al. (2006). In order to minimize possible risk of bias in the risk assessment of bias of the studies, two reviewers independently evaluated the results, calculating the inter-judge agreement index using the kappa coefficient (Cohen, 1960). Afterwards, the reviewers compared their scores and in the cases of disagreements a third reviewer was included to obtain a final consensus.

\section{Classification of strength of evidence}

The goal of strength of evidence assessments is to provide clearly explained, well-reasoned judgments about reviewers' confidence in their systematic review conclusions (Atkins, Fink, \& Slutsky, 2005). The classification of the strength of evidence of the main results of the studies was performed through the Grading Strength of Evidence system (Berkman et al., 2013). This system allowed to classify the results of the studies in five domains (study limitations, directness, consistency, precision, reporting bias). Subsequently, the strength of the results was classified into one of four levels: high, moderate, low, or insufficient (Berkman et al., 2013). Two reviewers individually assessed the strength of evidence from the study results and calculated the inter-judge agreement index using the kappa coefficient (Cohen, 1960). Subsequently both reviewers compared their scores and in cases of divergence a third reviewer was included in obtaining a final consensus.

\section{RESULTS}

\section{Selection of studies}

The different stages of research with the number of studies reviewed in each phase and the reasons for their exclusion are presented in figure 1. After the removal of duplicate studies $(\mathrm{n}=$ 278), a total of 480 articles were reviewed based on the title and abstract. This review allowed to exclude 451 studies where 426 articles were considered irrelevant, eighteen studies did not meet the defined age criteria and 7 trials evaluated individuals with specific pathologies. Thus, twenty-nine potentially relevant articles 
were selected for a full text revision process. After the complete review of the studies a total of fourteen articles were excluded, according to the defined eligibility criteria. Thus, fifteen studies were included in the review.

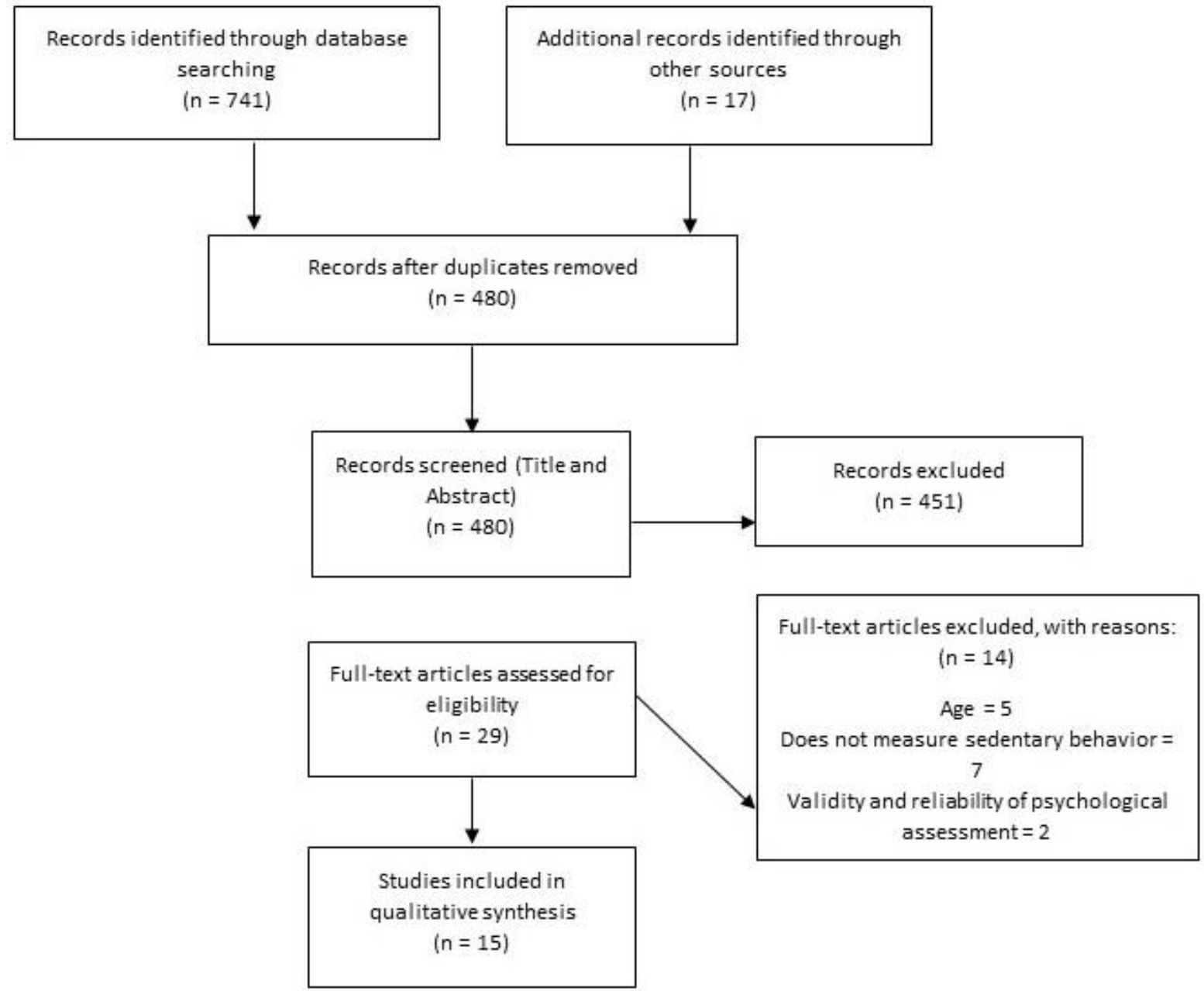

Figure 1. Prisma diagram of the study selection process.

\section{Characteristics of the studies}

Table 1 shows an overview of the main features of the studies included in the review. It was possible to verify that 8 studies followed a transversal design, whereas 7 articles used a longitudinal design. Regarding the follow-up period, longitudinal studies ranged from 18 months (Ku, Fox, Liao, Sun, \& Chen, 2016b) to 8 years (Ku, Fox, \& Chen, 2016a). The study participants were mostly recruited from specific communities in the countries where they were conducted. However, some trials recruited individuals from national representative samples (Gardner, Lliffe, Fox, Jefferis, \& Hamer, 2014; Hamer, Poole, \& Messerli-Bürgy, 2013; Hamer \& Stamatakis, 2014; $\mathrm{Ku}$ et al., 2016a; Ku et al., 2016b). The main criteria for selecting the participants were age-based, from the age of 60 years old, and in the elderly who demonstrated independence in performing daily life activities. Most of the studies selected the participants by probabilistic sampling methods, and these belonged to urban environments of different ethnicities. Regarding the evaluation of the sedentary behaviour, it was verified that the studies used self-reporting and objective measurement (accelerometers). With regard to psychological assessment, the articles used different measures, using scales of evaluation of different psychological indicators, tests of evaluation of cognitive functions and multidimensional scales that include psychological components. 
Table 1

Characteristics of selected studies

\begin{tabular}{|c|c|c|c|c|c|c|c|}
\hline \multirow[b]{2}{*}{ Author (year) } & \multirow[b]{2}{*}{ Country } & \multirow[b]{2}{*}{ Design } & \multicolumn{3}{|c|}{ Participants } & \multirow[b]{2}{*}{ Sedentary Behaviour Assessment } & \multirow[b]{2}{*}{ Psychological Assessment } \\
\hline & & & N Total & $\mathrm{N}(\mathrm{M} / \mathrm{F})$ & $\begin{array}{l}\text { Average } \\
\text { (SD) } \\
\text { Interval }\end{array}$ & & \\
\hline Lord et al. (2011) & England & $\begin{array}{c}\text { Cross- } \\
\text { sectional }\end{array}$ & 56 & $\begin{array}{l}26(\mathrm{M}) \\
30(\mathrm{~F})\end{array}$ & $78.9 \pm 4.9$ & ActivPAL accelerometer (7 days of use) & $\begin{array}{c}\text { Cambridge Neuropsychological Automated Testing Battery; } \\
\text { National Adult Reading Test; Mini Mental State Examination (MMSE); } \\
\text { Becks Depression Inventory; State Trait Anxiety Inventory; }\end{array}$ \\
\hline Withall et al. (2014) & England & $\begin{array}{c}\text { Cross- } \\
\text { sectional }\end{array}$ & 228 & $\begin{array}{l}117(\mathrm{M}) \\
111(\mathrm{~F})\end{array}$ & $\begin{array}{l}78.2 \pm 5.8 \\
70-96\end{array}$ & Actigraph accelerometer (7 days of use) & $\begin{array}{l}\text { Satisfaction with Life Scale (SWLS); SF-12 Mental health; Ageing Well } \\
\text { Profile. }\end{array}$ \\
\hline Buman et al. (2010) & EUA & $\begin{array}{c}\text { Cross- } \\
\text { sectional }\end{array}$ & 862 & $\begin{array}{l}44 \%(\mathrm{M}) \\
56 \%(\mathrm{~F})\end{array}$ & $75.4 \pm 6.8$ & Actigraph accelerometer ( 7 days of use) & $\begin{array}{c}\text { 1- Lee's Confusion Item; 1-item Kidney Depression Disease Quality of } \\
\text { Life Short Form, Version 1.3; 1--item satisfaction with the life of Social } \\
\text { Indicators of Well-Being: American's Perceptions of Life Quality; 13- } \\
\text { itens Cognitive Assessment Screening Test (CAST); 4-item Cohen } \\
\text { Perceived Stress Scale (PSS). }\end{array}$ \\
\hline Kikuchi et al. (2014) & Japan & $\begin{array}{c}\text { Cross- } \\
\text { sectional }\end{array}$ & 1580 & $\begin{array}{l}826(\mathrm{M}) \\
754(\mathrm{~F})\end{array}$ & $\begin{array}{l}69.5 \pm 2.9 \\
65-74\end{array}$ & $\begin{array}{l}\text { Self-report of the frequency and average duration (minutes / day) of the } \\
\text { last } 7 \text { days in the following behaviours: TV viewing, computer use, } \\
\text { reading, listening or speaking when sitting, sitting. }\end{array}$ & Psychological stress scale K6 \\
\hline Maher e Conroy (2017) & EUA & $\begin{array}{c}\text { Cross- } \\
\text { sectional }\end{array}$ & 100 & $\begin{array}{l}33(\mathrm{M}) \\
67(\mathrm{~F})\end{array}$ & $\begin{array}{c}74.2 \pm 8.2 \\
60-89\end{array}$ & $\begin{array}{l}\text { ActivPAL } 3 \text { accelerometer (14 days of use); Self-reporting of sedentary } \\
\text { behaviour for } 14 \text { days (see TV, computer use, reading, socializing with } \\
\text { friends, hobbies, time sitting in traffic, eating, office work, other } \\
\text { activities). }\end{array}$ & $\begin{array}{l}\text { 1-item Satisfaction with Life Scale (SWLS) modified for daily } \\
\text { administration }\end{array}$ \\
\hline Meneguci et al. (2015) & Brazil & $\begin{array}{c}\text { Cross- } \\
\text { sectional }\end{array}$ & 3206 & $\begin{array}{l}1236(\mathrm{M}) \\
1970(\mathrm{~F})\end{array}$ & $60-80+$ & $\begin{array}{l}\text { International Physical Activity Questionnaire; (IPAQ): time sitting on a } \\
\text { day if week and weekend (home, work, leisure, social visits, reading, } \\
\text { watching TV, lying down). }\end{array}$ & $\begin{array}{l}\text { WHOQOL-BREF; } \\
\text { WHOQOL-OLD. }\end{array}$ \\
\hline Ronch et al. (2015) & $\begin{array}{l}\text { Italy, } \\
\text { Switzerland, } \\
\text { Germany }\end{array}$ & $\begin{array}{c}\text { Cross- } \\
\text { sectional }\end{array}$ & 1383 & $\begin{array}{l}725(\mathrm{M}) \\
658(\mathrm{~F})\end{array}$ & $\begin{array}{l}72.5 \pm 5.6 \\
65-84\end{array}$ & TV viewing time in last week (self-reporting). & $\begin{array}{l}\text { Composite International Diagnostic Interview for the Elderly (CIDI65+); } \\
\text { Mini Mental State Examination (MMSE). }\end{array}$ \\
\hline Rosenberg et al. (2016) & EUA & $\begin{array}{c}\text { Cross- } \\
\text { sectional }\end{array}$ & 307 & $\begin{array}{l}85(\mathrm{M}) \\
222(\mathrm{~F})\end{array}$ & $\begin{array}{c}83.6 \pm 6.4 \\
67-100\end{array}$ & $\begin{array}{l}\text { Sedentary Behaviour Questionnaire (SBQ); } \\
\text { Accelerometer GT3X + Actigraph (6 days of use). }\end{array}$ & $\begin{array}{c}\text { Centre of Epidemiological Studies Depression (CES-D) scale; 12-item } \\
\text { adaptation of the Perceived Quality of Life Scale; 4-item Cohen Perceived } \\
\text { Stress Scale (PSS); Trail Making Test A \& B. }\end{array}$ \\
\hline Hamer et al. (2013) & England & Longitudinal & 4964 & $\begin{array}{l}43 \%(\mathrm{M}) \\
57 \%(\mathrm{~F})\end{array}$ & $64.5 \pm 8.9$ & TV viewing time (self-reporting). & Centre of Epidemiological Studies Depression (CES-D) scale \\
\hline Gardner et al. (2014) & England & Longitudinal & 6090 & $\begin{array}{l}45.2 \%(\mathrm{M}) \\
54.8 \%(\mathrm{~F})\end{array}$ & $64.9 \pm 8.9$ & TV viewing time (self-reporting). & Centre of Epidemiological Studies Depression (CES-D) scale \\
\hline $\begin{array}{l}\text { Hamer e Stamatakis } \\
\text { (2014) }\end{array}$ & England & Longitudinal & 6359 & $\begin{array}{l}45.2 \%(\mathrm{M}) \\
54.8 \%(\mathrm{~F})\end{array}$ & $64.9 \pm 9.1$ & $\begin{array}{l}\text { TV viewing time (self-reporting); Questions about internet usage and } \\
\text { reading habits, without time being counted. }\end{array}$ & $\begin{array}{l}\text { Centre of Epidemiological Studies Depression (CES-D) scale; Semantic } \\
\text { memory test; Verbal fluency test. }\end{array}$ \\
\hline $\begin{array}{l}\text { Kesse-Guyot et al. } \\
\text { (2012) }\end{array}$ & France & Longitudinal & 2579 & $\begin{array}{l}1425(\mathrm{M}) \\
1154(\mathrm{~F})\end{array}$ & $65.6 \pm 4.5$ & $\begin{array}{l}\text { Modifiable Activity Questionnaire: computer usage time, TV viewing } \\
\text { time, reading time. }\end{array}$ & $\begin{array}{l}\text { Semantic memory test of the Neuropsychological Assessment (Lezak); } \\
\text { RI-48 episodic memory test; Work memory test; Delis-Kaplan Executive } \\
\text { Function System mental flexibility test. }\end{array}$ \\
\hline Ku et al. (2016a) & Thailand & Longitudinal & 1268 & $\begin{array}{l}642(\mathrm{M}) \\
626(\mathrm{~F})\end{array}$ & $70-80+$ & $\begin{array}{l}\text { Frequency self-reporting (daily, weekly, monthly) about the following } \\
\text { behaviours: TV viewing, social talk, reading, listening to the radio, } \\
\text { playing chess / cards. }\end{array}$ & 10-itens version Life Index A (LSIA) \\
\hline Ku et al. (2016b) & Thailand & Longitudinal & 295 & $\begin{array}{l}43.1 \%(\mathrm{M}) \\
56.9 \%(\mathrm{~F})\end{array}$ & $65-75+$ & GT3X + Actigraph accelerometer (7 days of use). & The Chinese Aging Well Profile \\
\hline $\begin{array}{l}\text { Balboa-Castillo et al. } \\
\qquad \text { (2011) }\end{array}$ & Spain & Longitudinal & 1097 & $\begin{array}{l}40.8 \%(\mathrm{M}) \\
59.2 \%(\mathrm{~F})\end{array}$ & $70.3 \pm 5.6$ & $\begin{array}{l}\text { Self-reporting of sedentary behaviour (eating, listening to music, } \\
\text { watching TV, reading, driving, knitting, etc.) during the week and } \\
\text { weekend. }\end{array}$ & SF-36 \\
\hline
\end{tabular}


Table 2

Risk of bias in selected studies

\begin{tabular}{|c|c|c|c|c|c|c|c|c|}
\hline & $\begin{array}{c}\text { Varies } \\
\text { Inclusion/exclusion } \\
\text { (Selection bias) }\end{array}$ & $\begin{array}{l}\text { Strategy differ for } \\
\text { recruiting participants } \\
\text { (Selection bias } \\
\text { confounding) }\end{array}$ & $\begin{array}{l}\text { Valid and reliable } \\
\text { measures (Detection } \\
\text { bias, confounding) }\end{array}$ & $\begin{array}{l}\text { Impact assessed loss } \\
\text { follow-up (Attrition } \\
\text { bias, detection bias) }\end{array}$ & $\begin{array}{l}\text { Primary outcomes } \\
\text { missing from the } \\
\text { results (Selective } \\
\text { outcome reporting) }\end{array}$ & $\begin{array}{c}\text { Confounding variables } \\
\text { analysis } \\
\text { (Confounding) }\end{array}$ & $\begin{array}{l}\text { Results believable } \\
\text { (Overall assessment) }\end{array}$ & Rating category quality \\
\hline Lord et al. (2011) & No & No & Yes & $\mathrm{n} / \mathrm{a}$ & No & Partial & Yes & Good \\
\hline Withall et al. (2014) & No & No & Yes & $\mathrm{n} / \mathrm{a}$ & No & Partial & Yes & Good \\
\hline Buman et al. (2010) & No & No & Yes & $\mathrm{n} / \mathrm{a}$ & No & Partial & Yes & Good \\
\hline Kikuchi et al. (2014) & No & No & Yes & $\mathrm{n} / \mathrm{a}$ & No & Partial & Yes & Fair \\
\hline Maher e Conroy (2017) & No & No & Yes & $\mathrm{n} / \mathrm{a}$ & No & Partial & Yes & Good \\
\hline Meneguci et al. (2015) & No & No & Yes & $\mathrm{n} / \mathrm{a}$ & No & Partial & Yes & Fair \\
\hline Ronch et al. (2015) & No & No & Yes & $\mathrm{n} / \mathrm{a}$ & No & Partial & Yes & Fair \\
\hline Rosenberg et al. (2016) & No & No & Yes & $\mathrm{n} / \mathrm{a}$ & No & Partial & Yes & Good \\
\hline Hamer et al. (2013) & No & No & Yes & Yes & No & Partial & Yes & Fair \\
\hline Gardner et al. (2014) & No & No & Yes & Yes & No & Partial & Yes & Fair \\
\hline Hamer \& Stamatakis (2014) & No & No & Yes & Yes & No & Partial & Yes & Fair \\
\hline Kesse-Guyot et al. (2012) & No & No & Yes & Yes & No & Partial & Yes & Fair \\
\hline Ku et al. (2016a) & No & No & Yes & Yes & No & Partial & Yes & Fair \\
\hline Ku et al. (2016b) & No & No & Yes & Yes & No & Partial & Yes & Good \\
\hline Balboa-Castillo et al. (2011) & No & No & Yes & Yes & No & Partial & Yes & Fair \\
\hline
\end{tabular}

Note. N / a: not applicable; Good: Studies that have the least bias and results that are considered valid; Fair: Studies are susceptible to some bias that is not sufficient to invalidate the results.

Table 3

Classification of evidence strength of study outcomes

\begin{tabular}{|c|c|c|c|c|c|c|c|c|}
\hline Outcome & $\begin{array}{c}\text { Study design: } \\
\mathrm{N}^{\circ} \text { studies (n) }\end{array}$ & Study limitations & Directness & Consistency & Precision & Reporting bias & Findings & $\begin{array}{c}\begin{array}{c}\text { Strength of } \\
\text { evidence }\end{array} \\
\end{array}$ \\
\hline $\begin{array}{l}\text { Depressive } \\
\text { symptoms }\end{array}$ & $\begin{array}{l}\text { Cross-sectional and } \\
\text { longitudinal: } 6 \text { (19159) }\end{array}$ & $\begin{array}{l}\text { Low (transversal) } \\
\text { Low (longitudinal) }\end{array}$ & Direct & Inconsistent & Precise & Suspected & $\begin{array}{l}\text { Some results indicated associations between passive sedentary activities and } \\
\text { depressive symptoms. Other results showed no associations. }\end{array}$ & Low \\
\hline Life satisfaction & $\begin{array}{l}\text { Cross-sectional and } \\
\text { longitudinal: } 3 \text { (4702) }\end{array}$ & $\begin{array}{l}\text { Low (transversal) } \\
\text { Low (longitudinal) }\end{array}$ & Direct & Inconsistent & Precise & Suspected & $\begin{array}{l}\text { The results indicated that there were no associations between the sedentary } \\
\text { time and the satisfaction with life. Other results showed that some sedentary } \\
\text { behaviours are associated with life satisfaction. }\end{array}$ & Low \\
\hline $\begin{array}{l}\text { Well-being and } \\
\text { quality of life }\end{array}$ & $\begin{array}{l}\text { Cross-sectional and } \\
\text { longitudinal: } 5 \text { (5767) }\end{array}$ & $\begin{array}{l}\text { Low (transversal) } \\
\text { Low (longitudinal) }\end{array}$ & Direct & Inconsistent & Precise & Suspected & $\begin{array}{l}\text { Some results indicated associations between sedentary activities and a } \\
\text { detention of well-being. Other results indicated that there were no } \\
\text { associations. }\end{array}$ & Low \\
\hline Stress perceived & $\begin{array}{l}\text { Cross-sectional: } 2 \\
\quad(1887)\end{array}$ & Low & Direct & Inconsistent & Precise & Suspected & $\begin{array}{l}\text { Association between passive sedentary behaviours and psychological stress. } \\
\text { Active behaviours were not associated with stress. Other results indicated that } \\
\text { there is no association between sedentary time and stress. }\end{array}$ & Low \\
\hline $\begin{array}{l}\text { Cognitive } \\
\text { functions }\end{array}$ & $\begin{array}{l}\text { Cross-sectional and } \\
\text { longitudinal: } 4 \text { (10377) }\end{array}$ & $\begin{array}{l}\text { Low (transversal) } \\
\text { Low (longitudinal) }\end{array}$ & Direct & Inconsistent & Precise & Suspected & $\begin{array}{l}\text { Not all sedentary behaviours were associated with adverse mental health. } \\
\text { Some behaviours may help maintain some cognitive functions. }\end{array}$ & Low \\
\hline
\end{tabular}

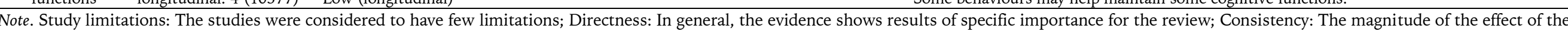

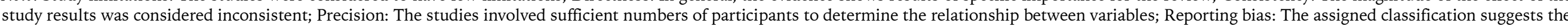

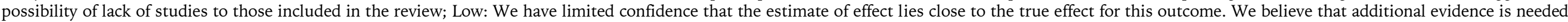
before concluding either that the findings are stable or that the estimate of effect is close to the true effect. 


\section{Risk of bias in individual studies}

The risk assessment for the bias of the studies is shown in table 2. The index of inter-judge agreement through the kappa coefficient (Cohen, 1960) was 0.70 , reason why it was considered good (Fleiss, 1981). Study rankings ranged from the fair to good level (Balk et al., 2006). With regard to the inclusion/exclusion criteria of study participants, it was found that they were explicitly defined. Regarding the instruments of measurement of sedentary behaviours, it was verified that they were valid as well as the psychological assessment. Concerning the confounding variables, it was observed that the studies took into account the analysis of some of these variables using statistical procedures to guarantee this control.

\section{Individual study results}

Table 3 shows the strength of evidence classification for each of the outcomes. All outcomes were classified at the low level according to the Grading Strength of Evidence criteria (Berkman et al., 2013). The index of inter-judges' agreement through the kappa coefficient (Cohen, 1960) was 0.60 and this value was considered good (Fleiss, 1981).

\section{Depressive symptoms}

Six articles (Gardner et al., 2014; Hamer \& Stamatakis, 2014; Hamer et al., 2013; Lord et al., 2011; Ronch et al., 2015; Rosenberg et al., 2016) investigated the relationship between sedentary behaviours and depressive symptoms. In the study by Lord et al. (2011), there were found no associations between sedentary behaviours time measured by accelerometer and depressive symptoms. These results appear to be in agreement with those of Rosenberg et al. (2016) who, through objective and self-report of evaluation of sedentary behaviours time, did not find associations between sedentary time and depressive symptoms. In the same sense, the research of Ronch et al. (2015) did not reveal associations between general diagnosis of depression and TV viewing time evaluated by self-report method. It was also found that individuals with depressive disorders tended to have less TV viewing time (Ronch et al., 2015).
However, in the article by Hamer et al. (2013), positive associations between TV viewing time and depressive symptoms were observed. Also, the research of Gardner et al. (2014) concluded that the increase in TV viewing time after followup was associated with the presence of depressive symptoms. The longitudinal study by Hamer and Stamatakis (2014) showed that, in the initial evaluation of the participants, the TV viewing time was associated with high levels of depression. It was also concluded that the elderly with more time of internet use showed less depressive symptoms. These results suggested that different sedentary behaviours were related in a different way to mental health components. However, after follow-up, no associations were found between the sedentary behaviours time and depressive symptoms (Hamer \& Stamatakis, 2014)

\section{Satisfaction with life}

In the research of Withall et al. (2014) no associations were found between the sedentary time and satisfaction with life. However, through the longitudinal study of $\mathrm{Ku}$ et al. (2016a), it was evidenced that some sedentary behaviours (watch TV, social talk, reading) were positively associated with satisfaction with life. Behaviours such as listening to radio and playing chess/cards were not associated with life satisfaction (Ku et al., 2016a). In the study by Maher and Conroy (2017), sedentary behaviour data objectively evaluated indicated that satisfaction with life was negatively associated with sedentary time. The data obtained through self-report measures revealed that the level of life satisfaction was not associated with sedentary behaviours time (Maher \& Conroy, 2017).

\section{Well-being and quality of life}

The study by Buman et al. (2010) through different measures of psychological evaluation concluded that the sedentary time in the elderly was negatively associated with the psychosocial well-being. In the work of Balboa-Castillo, LeónMuñoz, Graciani, Rodríguez-Artalejo and Guallar-Castillón (2011), it was concluded that the number of hours of seated time revealed an inverse relation with regard to social functions 
and mental health. However, in the longitudinal study of Ku et al. (2016b) it was verified that the sedentary time was not associated to the psychological dimension of well-being. In the cross-sectional investigation of Meneguci, Sasaki, Santos, Scatena and Damião (2015), it was also verified that long periods of sitting time did not contribute to a negative impact on psychological components in the quality of life of the elderly. Also, the results of the work by Rosenberg et al. (2016) did not show associations between the time of sedentary behaviours time and the quality of life of the elderly.

\section{Stress perceived}

The study by Rosenberg et al. (2016) did not find associations between sedentary behaviours time and perceived stress. The investigation by Kikuchi et al. (2014) showed that too much time of passive sedentary behaviours (TV, talk sitting and sitting) were associated with a greater probability of psychological stress. However, the time of active sedentary behaviours (computer use and reading) was not associated with psychological stress (Kikuchi et al., 2014).

\section{Cognitive functions}

Four studies have investigated the relationship between different cognitive functions and sedentary behaviours of the elderly population (Hamer \& Stamatakis, 2014; KesseGuyot et al., 2012; Lord et al., 2011; Ronch et al., 2015). The investigation by Lord et al. (2011) did not find associations between sedentary behaviours and cognitive functions of the elderly. However, the cross-sectional study by Ronch et al. (2015) found significant inverse correlations between the Mini Mental State Evaluation scores and the TV viewing time of elderly people from different European countries (Germany, Italy and Switzerland). The longitudinal investigation of Kesse-Guyot et al. (2012) concluded that specific sedentary behaviours were differentially associated with cognitive performance. In contrast to TV viewing, regular computer use can help to maintain cognitive functions, namely verbal memory and working memory during the aging process (Kesse-Guyot et al., 2012). In the same sense, the Hamer and Stamatakis longitudinal test (2014) showed that TV viewing time was associated with low levels of cognitive functions. However, the elderly with more time of internet use showed higher rates of cognitive functions, suggesting that not all sedentary behaviours are related to the adverse mental health of the elderly. However, after follow-up, no associations were found between sedentary behaviours and the cognitive functions evaluated, among them semantic memory (Hamer \& Stamatakis, 2014).

\section{DISCUSSION}

This systematic review aimed to synthesize the scientific evidence about the relationship between sedentary behaviours and various psychological outcomes in older adults. Most of the included studies were cross-sectional design $(\mathrm{n}=8)$ and longitudinal design studies $(\mathrm{n}=7)$. Regarding the psychological outcomes, the studies investigated depressive symptoms, life satisfaction, well-being and quality of life, perceived stress and certain cognitive functions. Evidences tended to show no association between the time of sedentary behaviours and the wellbeing and quality of life of the elderly. However, with regard to life satisfaction and perceived stress, it appears that active sedentary activities (e.g. reading, chatting, computer use) provided better life satisfaction and less psychological stress. In the same sense, the evidences suggested that some sedentary behaviours (e.g. computer use, reading) may help maintain some cognitive functions in the elderly population, namely in different types of memory. In other studies, it has also been shown a tendency that too much time of passive sedentary activities (e.g. watching TV) is associated with the depressive symptomatology of the elderly. However, each outcome was classified at the low level. This means that we have limited confidence that the effect estimate is close to the true effect for that result. We believe that additional evidence is needed concluding that the results are stable or that the effect is close to the true effect (Berkman et al., 2013).

Regarding the association between sedentary behaviours and depressive symptoms, the evidence seems to be in agreement with Atkin, 
Adams, Bull, and Biddle (2012), where habits of reading and internet use were associated with fewer depressive symptoms. In fact, passive sedentary activities such as TV viewing may stimulate social isolation and limit the development of social support networks being associated with depression (Golden et al., 2009). Thus, it seems that internet use stimulates social interaction, preventing the risk of deterioration of mental health in the elderly (Hamer \& Stamatakis, 2014).

In the relationship between different sedentary behaviours with satisfaction with life and well-being, the results found could be related to the representation of the use of time perceived by the elderly. In this sense, this perception of time in different sedentary behaviours can be determined by the values, interests and goals of the elderly, as well as the level of pleasure (Salmon, Owen, Crawford, Bauman, \& Sallis, 2003). In fact, some studies (Lu, 2011; Östlund, 2010) suggested that sedentary leisure activities that contemplate cognitive and social components are beneficial to subjective wellbeing, since they satisfy various aspects of psychological, social and relaxation needs. Nature sedentary activity may be important in understanding the relationships between sedentary behaviours and life satisfaction (Maher \& Conroy, 2017). Thus, the sedentary time may be considered by the elderly as an opportunity to rest and relax (Withall et al., 2014). Effectively, active seniors also experienced high levels of sedentary time (Davis et al., 2011). Also, the social norms of which being sedentary is normal when one is old, may explain the absence of a negative impact of sedentary time on life satisfaction (Withall et al., 2014). As verified by Hamer and Stamatakis (2014), different sedentary behaviours may be related in a different way to components of mental health. Therefore, it is also possible that, through the total amount of sedentary time, it has not been possible to verify associations consistent with psychological well-being dimensions ( $\mathrm{Ku}$ et al., 2016b). However, other studies have found that long periods of sitting had a negative impact on the quality of life of the elderly. These associations can be explained by the relationship between sedentary behaviour and the level of physical fitness. According to some studies (Hamer \& Stamatakis, 2013; Santos et al., 2012), individuals with high levels of sedentary behaviours revealed poor physical fitness and this is usually associated with a lower quality of life in the elderly population (Olivares, Gusi, Prieto, \& Hernandez-Mocholi, 2011). Moreover, psychological disturbances may also explain poorer quality of life associated with sedentary behaviours (Sloan et al., 2013).

Regarding the associations between sedentary behaviours and perceived stress, the results found could be related to the fact that active sedentary time is associated with greater social interaction in the elderly (Cotten, Anderson, \& McCullough, 2013). In this way, active sedentary activities, such as reading time, can provide a mental stimulation and thus help the elderly in the participation of other activities (Gallucci et al., 2009). Regarding the relationship between sedentary behaviours and cognitive functions, the results are in agreement with those found in the review by Rezende et al. (2014). It was verified that certain sedentary behaviours were protective of the state of mental health of the elderly. Thus, it seems that, for example, computer use may have mentally stimulating characteristics, and may compensate for its relatively passive nature in relation to its impact on brain aging (KesseGuyot et al., 2012).

\section{Limitations}

Fifteen studies were included in this review, which may be considered as a basis of limited scientific evidence. In this way, the analysis should be interpreted with caution. Due to a large number of variables that may influence the results of the studies, it is possible that they may influence the different domains of the sedentary behaviours and the indicators analysed. For example, although the results suggested that some sedentary behaviours were related to some analysed indicators, this review has not determined the exact relevance of other variables such as demographic factors, socioeconomic level, functional level and types of sedentary activities, in these results. In this sense, it became difficult to determine a direct cause and effect 
relationship between the sedentary behaviours and the different indicators analysed. Thus, more studies will be needed in order to elucidate how the moderating variables influence the relationships between sedentary behaviours and psychological indicators of the elderly. The analysis should also be made with caution given that not all the studies used representative samples. Therefore, it would be advisable that future studies with national representative samples should be considered. Another limitation of this review concerns the risk of bias of the studies, especially in relation to the instruments of measurement of the sedentary behaviours. The use of self-reporting measures may present a greater risk of data bias, since they estimated errors in the evaluation of the total time of sedentary behaviours (Healy et al., 2011). Thus, it is suggested that future studies may include self-reporting and objective measurement (accelerometers) simultaneously, as recommended in the assessment of sedentary behaviours (Chastin, Scwartz, \& Skelton, 2013). Another limitation was related to the research process of the studies. Although this has been rigorous, the revision may be subject to reporting bias that could be overcome through a funnel plot. Furthermore, study research was delimited for studies published in peer-reviewed journals and written in English only. Subsequently, other reviews may consider other languages in the selection process of the studies.

\section{Suggestion for future studies}

Since it seems that the relationship between sedentary behaviours and different psychological indicators is not a simple linear coincidence, more complex designs should be used in the future. In this way, it would be pertinent to find other investigations through longitudinal and experimental designs, allowing to establish a more robust causal relation between sedentary behaviours of the elderly and diverse psychological indicators. In this respect, should be considered other studies that investigate other psychological indicators such as resilience (Wagnild \& Young, 1993), adjustment to aging (von Humboldt, Leal, Pimenta, \& Maroco, 2014), manifestation of psychological well-being (Massé et al., 1998) and imagery (Mendes et al., 2016), according to different sedentary behaviours (active or passive) or the total sedentary time. It would also be pertinent to consider conducting qualitative investigations, with different methodological approaches, in order to understand in greater depth the perceptions of the elderly and new psychological dimensions that may be associated with sedentary behaviours.

\section{CONCLUSION}

There was a limited causal evidence between the sedentary behaviours and the psychological indicators analysed, since many conclusions came from cross-sectional studies. However, due to longitudinal design studies, it was possible to deepen the knowledge about the relationships between sedentary behaviour and the indicators analysed over time. Because of the different psychological measurement instruments, as well as the different methods of assessing sedentary behaviour, the existence of differentiated populations, as well as the differences in the research designs, there was a high heterogeneity of results, not allowing, consistently, to establish strong evidence relationships between sedentary behaviours and depression, well-being and quality of life, life satisfaction, perceived stress and certain cognitive functions. Thus, this review suggested that the evidence is not yet consistent in the relationship between the sedentary behaviours of the elderly and the analysed indicators, and more research is needed.

Acknowledgments:
Nothing to declare

Conflict of interests:

Nothing to declare.

\section{Funding:}

Nothing to declare.

\section{REFERENCES}

Atkin, A., Adams, E., Bull, F., \& Biddle, S. (2012). Non-occupational sitting and mental well-being in employed adults. Annals of Behavioral Medicine, 
43(2), 181-188. doi: 10.1007/s12160-011-9320$\mathrm{y}$.

Atkins, D., Fink, K., \& Slutsky, J. (2005). Better Information for Better Health Care: The Evidence-based Practice Center Program and the Agency for Healthcare Research and Quality. Annals of Internal Medicine, 142, 1035-41. doi: 10.7326/0003-4819-142-12_Part_2-20050621100002

Balboa-Castillo, T., León-Muñoz, L., Graciani, A., Rodríguez-Artalejo, F., \& Guallar-Castillón, A. (2011). Longitudinal association of physical activity and sedentary behavior during leisure time with health-related quality of life in community-dwelling older adults. Health and Quality of Life Outcomes, 9, 1-10. doi: 10.1186/1477-7525-9-47.

Balk, E., Raman, G., Chung, M., Ip, S., Tatsionl, A., Alonso, A., ... Lau, J. (2006). Effectiveness of Management Strategies for Renal Artery Stenosis: A Systematic Review. Annals of Internal Medicine, 145, 901-912.

Bauman, A., Reis, R., Sallis, J., Wells, J., Loos, R., \& Martin, B. (2012). Correlates of physical activity: Why are some people physically active and others not? Lancet, 380, 258-271.

Berkman, N., Lohr, K., Ansari, M., McDonagh, M., Balk, E., Whitlock, E., ... Chang, S. (2013). Grading the Strength of a Body of Evidence When Assessing Health Care Interventions for the Effective Health Care Program of the Agency for Healthcare Research and Quality: An Update. Rockville, MD: AHRQ Publication.

Buman, M., Hekler, E., Haskell, W., Pruitt, L., Conway, T., Cain, K., ... King, A. (2010). Objective LightIntensity Physical Activity Associations With Rated Health in Older Adults. American Journal of Epidemiology, 172, 1155-1165. doi: 10.1093/aje/kwq249.

Chastin, S. F. M., Buck, C., Freiberger, E., Murphy, M., Brug, J., Cardon, G., ... DEDIPAC consortium. (2015). Systematic literature review of determinants of sedentary behaviour in older adults: a DEDIPAC study. The International Journal of Behavioral Nutrition and Physical Activity, 12, 127. https://doi.org/10.1186/s12966-015-02923

Chastin, S. F. M., Schwarz, U., \& Skelton, D. A. (2013). Development of a Consensus Taxonomy of Sedentary Behaviors (SIT): Report of Delphi Round 1. PLoS One, 8(12), e82313. https://doi.org/10.1371/journal.pone.0082 313

Cohen, J. (1960). A coefficient of agreement for nominal scales. Educational and Psychological Measurement, 20, 37-46.

Cotten, S., Anderson, W., \& McCullough, B. (2013). Impact of internet use on loneliness and contact with others among older adults: cross-sectional analysis. Journal of Medical Internet Research, 15(2), e39. doi: 10.2196/jmir.2306.
Davis, M., Fox, K., Hillsdon, M., Coulson, J., Sharp, D., Stathi, A., \& Thompson, J. (2011). Getting out and about in older adults: The nature of daily trips and their association with objectively assessed physical activity. International Journal of Behavioral Nutrion and Physical Activity, 8, 116-125. doi: 10.1186/1479-5868-8-116

Faulkner, G., \& Biddle, S. (2013). Standing on top of the world: Is sedentary behavior associated with mental health? Mental Health and Physical Activity, 6, 1-2. doi: 10.1016/j.mhpa.2013.02.003.

Fleiss, J. (1981). Statistical methods for rates and proportions $\left(2^{\text {th }}\right.$ ed.). New York: John Wiley \& Sons.

Gallucci, M., Antuono, P., Ongaro, F., Forloni, P., Albani, D., Amici, G., \& Regini, C. (2009). Physical activity, socialization and reading in the elderly over the age of seventy: what is the relation with cognitive decline? Evidence from "The Treviso Longeva (TRELONG) study". Archives of Gerontology and Geriatrics, 48(3), 284286. doi: 10.1016/j.archger.2008.02.006.

Gardner, B., Iliffe, S., Fox, K. R., Jefferis, B. J., \& Hamer, M. (2014). Sociodemographic, behavioural and health factors associated with changes in older adults' TV viewing over 2 years. International Journal of Behavioral Nutrition and Physical Activity, 11, 102. https://doi.org/10.1186/s12966-014-0102-3

Golden, J., Conroy, R., Bruce, I., Denihan, A., Greene, E., Kirby, M., \& Lawlor, B. (2009). Loneliness, social support networks, mood and wellbeing in community-dwelling elderly. International Journal of Geriatric Psychiatry, 24(7), 694-700. doi: 10.1002/gps.2181.

Hamer, M., \& Stamatakis, E. (2013). Screen-based sedentary behavior, physical activity, and muscle strength in the English longitudinal study of ageing. PLoS One, 8(6), e66222. doi: 10.1371/journal.pone.0066222.

Hamer, M., \& Stamatakis, E. (2014). Prospective Study of Sedentary Behaviour, Risk of Depression, and Cognitive Impairment. Medicine and Science in Sports and Exercise, 46(4), 718-723. doi: 10.1249/MSS.0000000000000156.

Hamer, M., Poole, L., \& Messerli-Bürgy, N. (2013). Television viewing, C-reactive protein, and depressive symptoms in older adults. Brain, Behavior, and Immunity, 33, 29-32. doi: 10.1016/j.bbi.2013.05.001.

Harvey, J., Chastin, S., \& Skelton, D. (2015). How sedentary are older people? A systematic review of the amount of sedentary behavior. Journal of Aging and Physical Activity, 23(3), 471-487. doi: 10.1123/japa.2014-0164.

Healy, G., Clark, B., Winkler, E., Gardiner, P., Brown, W., \& Matthews, C. (2011). Measurement of adults' sedentary time in population-based studies. American Journal of Preventive Medicine, $41(2)$, 216-27. 10.1016/j.amepre.2011.05.005. 
Hoare, E., Milton, K., Foster, C., \& Allender, S. (2016). The associations between sedentary behaviour and mental health among adolescents: a systematic review. International Journal of Behavioral Nutrition and Physical Activity, 13, 108. doi: 10.1186/s12966-016-0432-4.

Katzmarzyk, P., Church, A., Craig, C., \& Bouchard, C. (2009). Sitting time and mortality from all causes, cardiovascular disease, and cancer. Medicine and Science in Sports and Exercise, 41, 998-1005. doi: 10.1249/MSS.0b013e3181930355.

Kesse-Guyot, E., Charreire, H., Andreeva, V., Touvier, M., Hercberg, S., Galan, P., \& Oppert, J. (2012). Cross-Sectional and longitudinal associations of different sedentary behaviors with cognitive performance in older adults. PLoS One, 7(10), e47831. doi: 10.1371/journal.pone.0047831.

Kikuchi, H., Inoue, S., Sugiyama, T., Owen, N., Oka, K., Nakaya, T., \& Shimomitsu, T. (2014). Distinct associations of different sedentary behaviors with health-related attributes among older adults. Preventive Medicine, 67, 335-339. doi: 10.1016/j.ypmed.2014.08.011.

Ku, P., Fox, K., \& Chen, L. (2016a). Leisure-Time Physical Activity, Sedentary Behaviors and Subjective Well-Being in Older Adults: An EightYear Longitudinal Research. Social Indicators Research, 127, 1349-1361. doi: 10.1007/s11205015-1005-7.

Ku, P., Fox, K., Liao, Y., Sun, W., \& Chen, L. (2016b). Prospective associations of objectively assessed physical activity at different intensities with subjective well-being in older adults. Quality of Life Research, 25, 2909-2919. doi: 10.1007/s11136-016-1309-3.

Lord, S., Chastin, S., Mclnnes, L., Little, L., Briggs, P., \& Rochester, L. (2011). Exploring patterns of daily physical and sedentary behaviour in community-dwelling older adults. Age and Ageing, 40, 205-210. doi: 10.1093/ageing/afq166.

Lu, L. (2011). Leisure experiences and depressive symptoms among Chinese older people: A national survey in Taiwan. Educational Gerontology, 37, 753-771. doi: 10.1080/03601271003744632.

Maher, J. P., \& Conroy, D. E. (2017). Daily Life Satisfaction in Older Adults as a Function of (In)Activity. The Journals of Gerontology: Series B, 72(4), 593-602. doi:10.1093/geronb/gbv086

Massé, R., Poulin, C., Dassa, C., Lambert, J., Bélair, S., \& Battaglini, A. (1998). Élaboration et validation d'un outil de mesure du bien-être psychologique: L'É.M.M.B.E.P. Revue Canadienne de Santé Publique, 89, 352-357. doi: 10.17269/cjph.89.1014.

Matthews, C., Chen, K., Freedson, P., Buchowski, M., Beech, B., Pate, R., \& Troiano, R. (2008). Amount of time spent in sedentary behaviors in the United States, 2003-2004. American Journal of Epidemiology, 167, 875-881. doi: 10.1093/aje/kwm390.

Mendes, P., Marinho, D., Petrica, J., Silveira, P., Monteiro, D., \& Cid, L. (2016). Tradução e Validação do Movement Imagery Questionnaire -
3 (MIQ-3) com Atletas Portugueses. Motricidade, 12(1), 149-158. doi: 10.6063/motricidade.7006.

Meneguci, J., Sasaki, J., Santos, A., Scatena, L., \& Damião, R. (2015). Sitting Time and Quality of Life in Older Adults: A Population-Based Study. Journal of Physical Activity and Health, 12, 15131519. doi: 10.1123/jpah.2014-0233.

Moher, D., Liberati, A., Tetzlaff, J., Altman, D. G., \& PRISMA Group. (2009). Preferred reporting items for systematic reviews and meta-analyses: the PRISMA statement. PLoS Medicine, 6(7), e1000097. https://doi.org/10.1371/journal.pmed.1000097

Olivares, P., Gusi, N., Prieto, J., \& Hernandez-Mocholi, M. (2011). Fitness and health-related quality of life dimensions in community-dwelling middle aged and older adults. Health and Quality of Life Outcomes, 9, 117. doi: 10.1186/1477-7525-9-117.

Östlund, B. (2010). Watching television in later life: A deeper understanding of TV viewing in the homes of old people and in geriatric care contexts. Scandinavian Journal of Caring Sciences, 24, 233243. doi: 10.1111/j.1471-6712.2009.00711.x.

Owen, N., Sugiyama, T., Eakin, E., Gardiner, P., Tremblay, M., \& Sallis, J. (2011). Adults“ sedentary behavior determinants and interventions. American Journal of Preventive Medicine, 41, 189-196. doi: 10.1016/j.amepre.2011.05.013.

Owen, N., Bauman, A., \& Brown, A. (2009). Too much sitting: a novel and important predictor of chronic disease risk? British Journal of Sports Medicine, 43, 81-83. doi:10.1136/bjsm.2008.055269.

Rezende, L., Rey-López, J., Matsudo, V., \& Carmo Luiz, O. (2014). Sedentary behavior and health outcomes among older adults: a systematic review. BMC Public Health, 14, 333. doi: 10.1186/1471-2458-14-333.

Ronch, C., Canuto, A., Volkert, J., Massarenti, S., Weber, K., Dehoust, M., ... Grassi, L. (2015). Association of television viewing with mental health and mild cognitive impairment in the elderly in three European countries, data from the MentDis_ICF65p project. Mental Health and Physical Activity, 8, 8-14. doi: 10.1016/j.mhpa.2014.11.002.

Rosenberg, D., Bellettiere, J., Gardiner, P., Villarreal, V., Crist, K., \& Kerr, J. (2016). Independent Associations Between Sedentary Behaviors and Mental, Cognitive, Physical, and Functional Health Among Older Adults in Retirement Communities. The Journals of Gerontology: Series A, 71 (1), 78-83. doi: 10.1093/gerona/glv103.

Salmon, J., Owen, N., Crawford, D., Bauman, A., \& Sallis, J. (2003). Physical activity and sedentary behavior: A population based study of barriers, enjoyment, and preference. Health Psychology, 22, 178-188.

Santos, D., Silva, A., Baptista, F., Santos, R., Vale, S., Mota, J., \& Sardinha, L. (2012). Sedentary behavior and physical activity are independently related to functional fitness in older adults. 
Experimental Gerontology, 47, 908-912. doi: 10.1016/j.exger.2012.07.011.

Sedentary Behaviour Research Network. (2012). Letter to the editor: Standardized use of the terms "sedentary" and "sedentary behaviours". Applied Physiology, Nutrition, and Metabolism, 37, 540-542. doi: 10.1001/jama.2011.812.

Sloan, R., Sawada, S., Girdano, D., Liu, Y., Biddle, S., \& Blair, S. (2013). Associations of sedentary behavior and physical activity with psychological distress: a cross-sectional study from Singapore. BMC Public Health, 13, 885. doi: 10.1186/14712458-13-885.

Stamatakis, E., Davis, M., Stathi, A., \& Hamer, M. (2012). Associations between multiple indicators of objectively-measured and self-reported sedentary behaviour and cardiometabolic risk in adults. Preventive Medicine, 54, 8287.doi:10.1016/j.ypmed.2011.10.009.

Teychenne, M., Costigan, S., \& Parker, K. (2015). The association between sedentary behavior and risk of anxiety: a systematic review. BMC Public Health, 15:513. doi: 10.1186/s12889-015-1843-x.
Vandenbroucke, J. (2011). Why do the results of randomised and observational studies differ? BMJ, 343, d7020. doi: 10.1136/bmj.d7020

Viswanathan, M., Berkman, N., Dryden, D., \& Hartling, L. (2013). Assessing Risk of Bias and Confounding in Observational Studies of Interventions or Exposures: Further Development of the RTI Item Bank. Rockville, MD: AHRQ Publication.

von Humboldt, S., Leal, I., Pimenta, F., \& Maroco, J. (2014). Assessing Adjustment to Aging: A Validation Study for the Adjustment to Aging Scale (AtAS). Social Indicators Research, 119, 455472. doi: 10.1007/s11205-013-0482-9.

Wagnild, G., \& Young, H. (1993). Development and psychometric evaluation of the Resilience Scale. Journal of Nursing Measurement, 1, 165-178.

Withall, J., Stathi, A., Davis, M., Coulson, J., Thompson, J., \& Fox, K. (2014). Objective indicators of physical activity and sedentary time and associations with subjective well-being in adults aged 70 and over. International Journal of Environmental Research and Public Health, 11(1), 643-56. doi: 10.3390/ijerph110100643.

All content of Journal Motricidade is licensed under Creative Commons, except when otherwise specified and in content retrieved from other bibliographic sources. 